\title{
DETERMINATION OF MATHEMATICAL MODEL OF AN ELECTRIC POWER SYSTEM USING LINEAR GRAPH
}

\author{
Adem ÜNAL \\ Department of Electrical Engineering \\ Yilduz Technical University, Istanbul 80750 - TR
}

\section{ABSTRACT}

The transformation of a physical system to mathematical base is very important due to analysis of the systems behaviour. In this study an electric power system is considered, and this system is characterized with first-order differantial eqautions therefore stateequations which define behaviour of the system for any instant " $t$ " are obtained.

\section{INTRODUCTION}

Exact solution and simulation of various engineering problems, "especially control engineering problems, depend on convenient mathematical models for elements and subsystems of the system considered. Process of the transformation of the system's behaviour to mathematical basis is called "mathematical modelling" $[1,2]$.

\section{DETERMINATION OF STATE-EQUATIONS OF A PHYSICAL SYSTEM}

When state-equation of the physical systems are determined, the methods which are known from Circuit Analysis Theory in Electrical Engineering may be successively used. Where, in order to obtain state-equations, lineer graph theory, very important technique is used [3-8].

During analysis, it is assumed that the solution of a physical system given is possible. As general definition, in a proper system, voltage and current sources may not mesh and cut, respectively. Therefore, in the system graph for a proper system, a tree that graphelements of voltage sources and current sources correspond to branch and link, respectively may be chosen [9-12]. If possible, all capacitance-type elements are put in branches of the tree and all inductance-type elements are out of the tree. This tree used for writting the equations is called "proper tree". State variables of the system are the voitages of capacitors in the branches and the currents of inductors out of the tree. Therefore, first-order differantial equations which consists of unknown voltages and currents are written. 


\section{A SAMPLE FOR DETERMINATION OF MATHEMATICAL MODEL}

Electric power system shown in Fig. 1 is considered as a physical system.

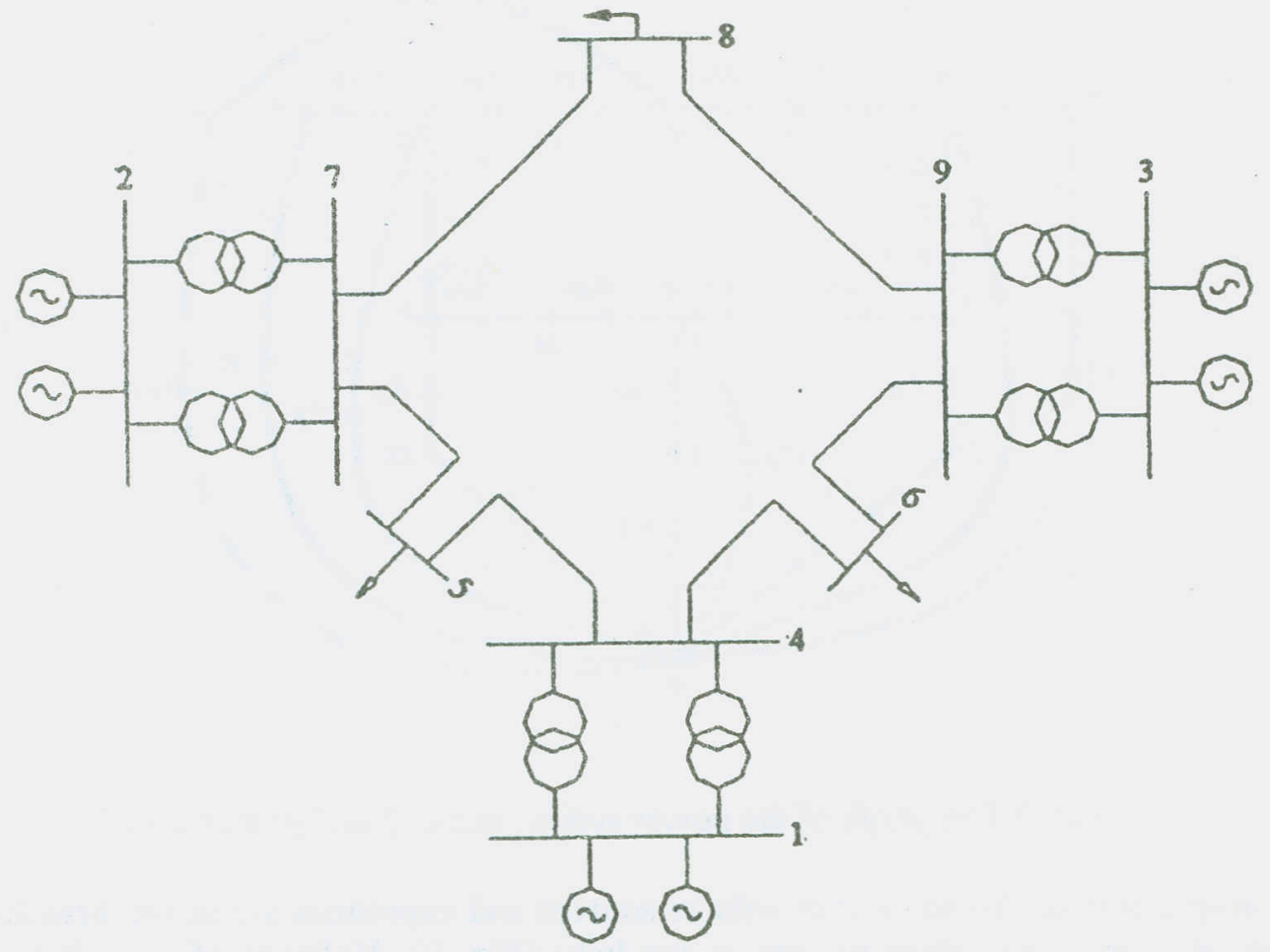

Fig. 1 Illustration of single line diagram of power system considered.

After the system's parameters are defined as circuit elements, the circuit in Fig. 2 is drawn.

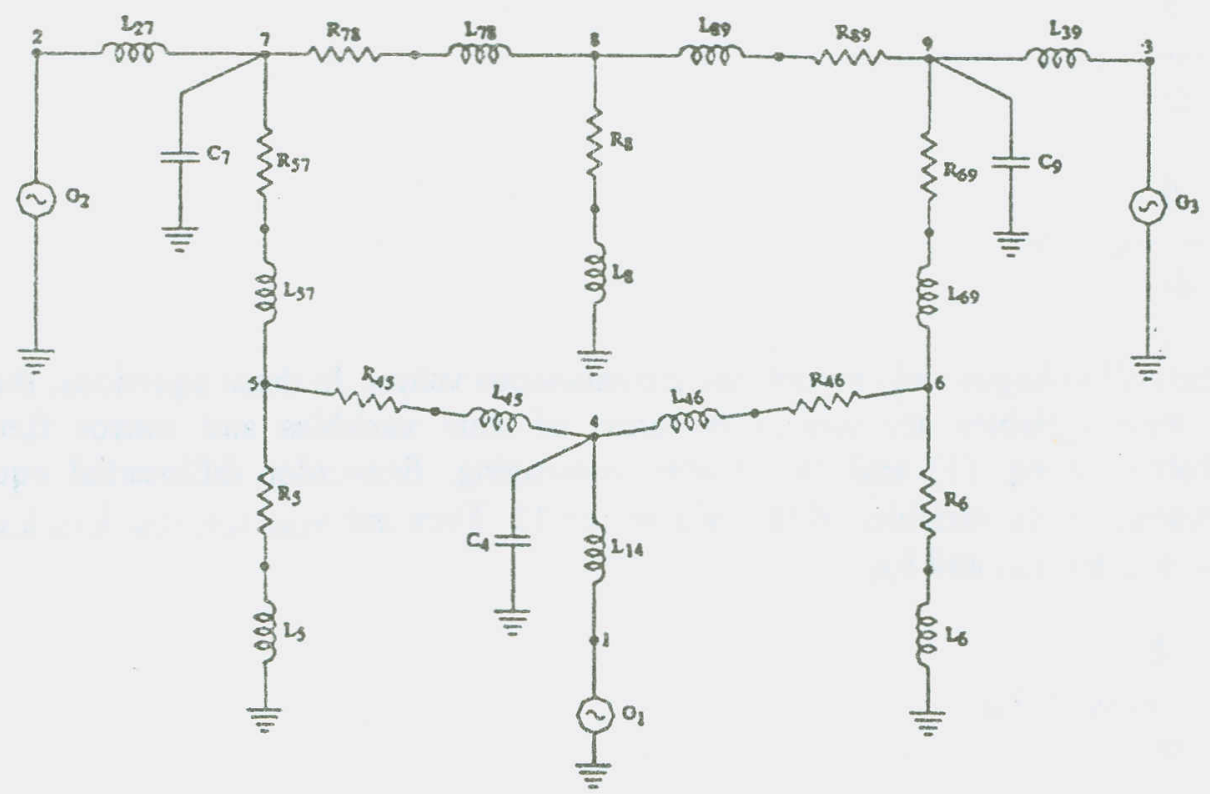

Fig. 2 Illustration of power system as an electrical circuit. 
Later, circuit's graph is drawn as shown in Fig. 3

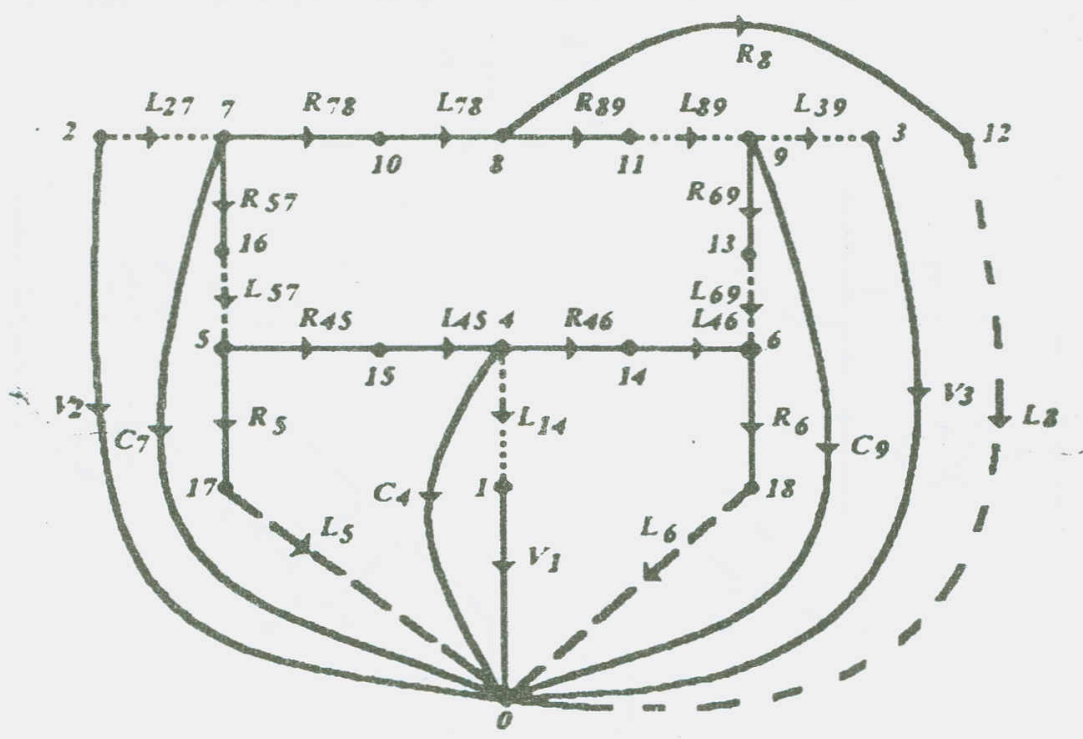

Fig. 3 The graph of the power system and chosen "proper tree."

A proper tree is chosen so that voltage sources and capacitors are in the branches and current sources and inductors are in the links (Fig. 3). Voltages of capacitors in the branches and currents of inductors in the links are state variables of the system. Derivative terminal equations are written as follows:

$$
\begin{gathered}
\frac{d}{d t}-v_{c}=i_{C} \\
L-\frac{d}{d t}-i_{L}=v_{L}
\end{gathered}
$$

where all voltages and currents are instantaneous values. In these equations, the terms out of state variables are written in terms of state variables and source functions. By substituting eq. (1) and eq.(2) and rearranging, first-order differential equations are obtained. State variables of the system are 12 . They are $v_{C 4}, v_{C 7}, v_{C 9}, i_{L 27}, i_{L 39}, i_{L 57}, i_{L 89}$, $\mathrm{i}_{\mathrm{L} 69}, \mathrm{i}_{\mathrm{L} 14}, \mathrm{i}_{\mathrm{L} 8}, \mathrm{i}_{\mathrm{L} 45}$ and $\mathrm{i}_{\mathrm{L} 46}$.

$$
\begin{aligned}
& \mathrm{C}_{4} \frac{\mathrm{d}}{\mathrm{dt}} \\
& \mathrm{i}_{\mathrm{C} 4}-\mathrm{i}_{\mathrm{L} 45}+\mathrm{i}_{\mathrm{L} 14}+\mathrm{i}_{\mathrm{L} 46}=0
\end{aligned}
$$


$\mathrm{i}_{\mathrm{C} 4}=\mathrm{i}_{\mathrm{L} 45}-\mathrm{i}_{\mathrm{L} 14}-\mathrm{i}_{\mathrm{L} 46}$

d

$\mathrm{C}_{4}-\mathrm{v}_{\mathrm{C} 4}=-\mathrm{i}_{\mathrm{L} 14}+\mathrm{i}_{\mathrm{L} 45}-\mathrm{i}_{\mathrm{L} 46}$

Finally, first-order differantial equations consisting of state variables (capacitor voltages) in the branches are obtained.

State-equations of inductors are also written:

$$
\begin{gathered}
\frac{d}{L_{27}--i_{L 27}=v_{L 27}} \\
v_{L_{22}}+v_{C 7}-V_{2}=0 \\
v_{L 27}=-v_{C 7}+V_{2} \\
\frac{d}{L_{27} \frac{d t}{d t} i_{L 27}=-v_{C 7}+V_{2}}
\end{gathered}
$$

All equations obtained may be written in matrix form as shown in eq. (11):

\section{CONCLUSIONS}

State-equations of an electric power system may be obtained step by step, using linear graph representation and proper tree technique, such as $\frac{\mathrm{d}}{d t} x(t)=A \underset{\approx}{A x}(t)+B \underset{\approx}{u}(t)$. Variations of currents and voltages versus time, which are state

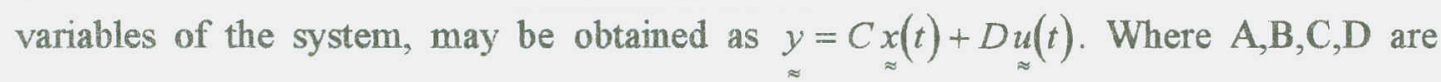
coefficients-matrices and $\approx$ denotes matrix representation. 


\begin{tabular}{|c|c|c|c|c|c|c|c|c|c|c|c|c|c|}
\hline $\mathrm{C}_{4}$ & 0 & 0 & 0 & 0 & 0 & 0 & 0 & 0 & 0 & 0 & 0 & & $\mathrm{v}_{\mathrm{C} 4}$ \\
\hline 0 & C7 & 0 & 0 & 0 & 0 & 0 & 0 & 0 & 0 & 0 & 0 & & $\mathbf{v}_{\mathrm{C} 7}$ \\
\hline 0 & 0 & C9 & 0 & 0 & 0 & 0 & 0 & 0 & 0 & 0 & 0 & & $v_{C 9}$ \\
\hline 0 & 0 & 0 & $\mathrm{~L}_{27}$ & 0 & 0 & 0 & 0 & 0 & 0 & 0 & 0 & & $\mathrm{i}_{\mathrm{L} 27}$ \\
\hline 0 & 0 & 0 & 0 & $\mathrm{~L}_{39}$ & 0 & 0 & 0 & 0 & 0 & 0 & 0 & & $i_{L 39}$ \\
\hline 0 & 0 & 0 & 0 & 0 & $\left(L_{57}+L_{45}\right)$ & 0 & 0 & 0 & $-\mathrm{L}_{45}$ & 0 & 0 & d & $i_{L 57}$ \\
\hline 0 & 0 & 0 & 0 & 0 & 0 & $\left(\mathrm{~L}_{89}+\mathrm{L}_{78}\right)$ & 0 & 0 & 0 & 0 & $\mathrm{~L}_{78}$ & $d t$ & $\mathrm{i}_{L 89}$ \\
\hline 0 & 0 & 0 & 0 & 0 & 0 & 0 & $\left(\mathrm{~L}_{69}+\mathrm{L}_{46}\right)$ & 0 & 0 & $-\mathrm{L}_{46}$ & & & $i_{L G 9}$ \\
\hline 0 & 0 & 0 & 0 & 0 & 0 & 0 & 0 & $\mathrm{~L}_{14}$ & 0 & 0 & 0 & & $i_{L 14}$ \\
\hline 0 & 0 & 0 & 0 & 0 & $-\mathrm{L}_{45}$ & 0 & 0 & 0 & $\left(L_{5}+L_{45}\right)$ & 0 & 0 & & $\mathrm{i}_{L S}$ \\
\hline 0 & 0 & 0 & 0 & 0 & 0 & 0 & $-I_{46}$ & 0 & 0 & $\left(\mathrm{~L}_{\sigma}+\mathrm{L}_{46}\right)$ & 0 & & $\mathrm{i}_{L 6}$ \\
\hline 0 & 0 & 0 & 0 & 0 & 0 & $\mathrm{~L}_{78}$ & 0 & 0 & 0 & 0 & $\left(\mathrm{~L}_{8}+\mathrm{L}_{78}\right)$ & & $\mathrm{i}_{\mathrm{L} 8}$ \\
\hline
\end{tabular}

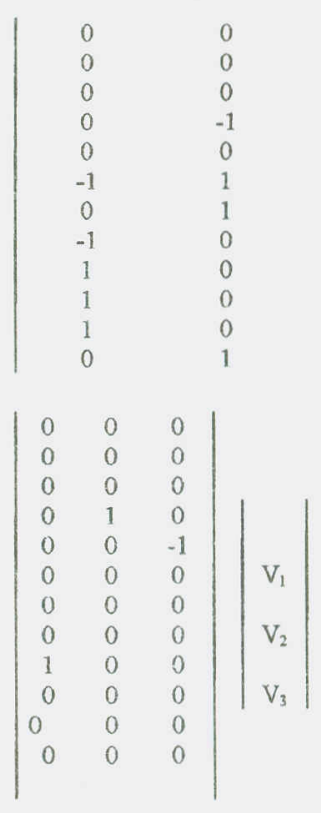

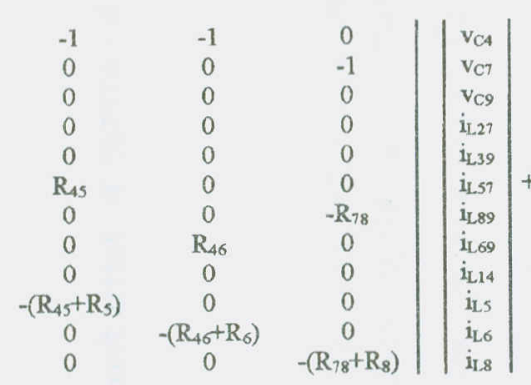




\section{REFERENCES}

[1] Tokad, Y., "Analysis of Engineering Systems-Part 2" (in Turkish), Yuldız University Press, Istanbul, 1985.

[2] Ünal, A., "Determination and Solution of State-Equations - Solved Problems" Cource Notes (in Turkish), Yildız University Press, Istanbul, 1986.

[3] Behzad, M. and Chantrand, G., "Introduction to the Theory of Graphs", Allyn and Bacon Inc., Boston, 1971.

[4] Alevi, Y., Lick, D.R. and White, A.T., "Graph Theory and Applications", SpringerVerlag, New York, 1972.

[5] Wilson, R.J., "Introduction to Graph Theory", Academic Press, New York, 1972.

[6] Berge, C., "Graphs and Hypergraphs", North-Holland Pub. Co., New York, 1973.

[7] Biggs, N., “Algebraic Graph Theory”, Cambridge University Press, 1974.

[8] Deo, N., "Graph Theory with Applications to Engineering and Computer Science", Printice-Hall, N.J., 1974.

[9] Abdy, P.R., "Applied Circuit Theory-Matrix and Computer Methods", Ellis Harwood, 1980.

[10] Papoulis, A., "Circuits and Systems: A Modern Approach", Holt Reinhart and Winston, New York, 1982.

[11] Johnson, D.E., et al., "Basic Electric Circuit Analysis, Prentice- Hall, 1986.

[12] Nilsson, J.W., "Electric Circuits", Addison- Wesley, 1986. 